\title{
SPECIAL
}

ARTICLE

\section{Matching 25\% of Medical Students in Family Medicine by 2030: Realistic or Beyond Our Reach?}

Alan K. David, MD

\begin{abstract}
This article examines the America Needs More Family Doctors: $25 \times 2030$ Collaborative goal of " $25 \times 30$ " - that $25 \%$ of all medical students will enter family medicine residency programs by the year 2030 . Filling $25 \%$ of all available postgraduate year-1 positions in the match is an important consideration in creating a strong primary care workforce. Data from the National Resident Matching Program (NRMP) matches for 2010 and 2020 are reviewed to examine trends not only in the US MD and DO categories, but also US international medical school graduates (IMGs) and non-US IMG categories over the last 10 years. If the total number of all programs and of all positions of-

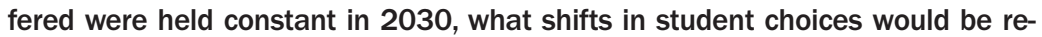
quired to reach the $25 \times 30$ goal in each applicant category as well as for all four categories combined? This discussion explores resources, power, physician income, and other factors that affect student numbers. Until a national health system is developed with national goals and priorities, it is unlikely that $25 \times 30$ will become a reality.
\end{abstract}

(Fam Med. 2021;53(4):252-5.)

doi: 10.22454/FamMed.2021.982403

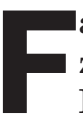
amily medicine (FM) organizations participating in the Family Medicine for America's Health (FMAH) project established a goal that $25 \%$ of allopathic and osteopathic students will choose FM first-year residency positions by $2030 .{ }^{1} \mathrm{FM}$ has committed enormous resources, energy, and thought toward teaching all students the principles of FM, which are an important part of all students' learning. Students experiencing FM with positive role modeling and mentoring might be more likely to choose FM as their specialty. The results have been mixed, at best, varying over the years due to forces not well defined or beyond the control of FM.
Physicians and students today work and learn in a dysfunctional health care system based on market forces motivated and designed to make ever greater profits for health systems, the pharmaceutical industry, insurance plans, and some large medical groups. ${ }^{2}$ Students are increasingly becoming aware of health disparities and inequities, especially in a country that does not provide universal health care for its citizens and has no national or rational health manpower policy or priorities. The COVID-19 pandemic and resulting economic recession leading to massive unemployment has laid bare the false security of employer-based health insurance, which has led to 10-20 million people ${ }^{3}$ now without coverage. Medical students' interpretations and internalizations of these market and societal forces likely influence their specialty choice.

While these recent events have also reemphasized the importance and need for a robust and much larger family physician workforce, what power does FM have to effect change, and how might those changes impact the 25x30 goal? Power can be defined as the ability to influence the ideas and conduct of others-this can be legitimized by social structures that can move and empower others as well. ${ }^{4}$ In an era of increased calls for universal health care, what power does FM, or even all of medicine, have to effect change of this magnitude? Knowing where we are now is important in knowing where we want to be.

\section{National Resident Matching Program (NRMP) Data}

Examining NRMP data trends over time can help clarify what progress has been made from $2010^{5}$ to $2020{ }^{6}$ thereby laying the groundwork for what magnitude of change may be needed to get to $25 \times 30$ by 2030 . Tables 1 and 2 use actual filled position

From the Department of Family and Community Medicine, Medical College of Wisconsin, Milwaukee, WI. 
data as a more accurate reflection of reality, rather than positions offered. Table 1 compares FM match data from 2010 to 2020, highlighting dramatic increases in the number of applicants in each of four categories. The total DO applicant pool increased $313 \%(1,444$ to 5,968$)$ and total FM programs increased $55 \%$ (454 to 706 ) over the 10-year time span. The increase in program numbers was not solely due to new programs. Beginning in 2015 and extending to 2020 , all graduate medical education program approval came under the auspices of one accrediting body, the Accreditation Council for Graduate Medical Education (ACGME). Previously, osteopathic programs had not participated in the ACGME process and had not been part of the NRMP or in its data set. The 5-year process was a one-time phenomenon and the movement to one accreditation and match process over the last 5 years is responsible for some of the program and position increases seen reflected in this time span analysis. In addition, new programs have been established by large health systems, state government funding and new Community Health Center (CHC) funding. The decline in the percentage of FM postgraduate year-1
(PGY-1) positions filled by US MD applicants (from 49\% in 2010 to $35 \%$ in 2020), is disconcerting. The total US MD pool of applicants is much larger than any other applicant pool category. Although raw numbers reveal a 10-year aggregate increase of 374 matched individuals, 37 per year on average or a $32 \%$ increase over the 10 year time span, this increase has not kept pace with the expanded number of positions offered (78.7\%), nor the increase in positions filled (80.9\%). The percentage of US MD individuals filling an FM position compared to all US MD individuals filling any type of PGY-1 position rose only from $7.8 \%$ to $8.5 \%$ during this 10-year time frame. Thus, getting $25 \%$ of US MD graduates to enter FM programs as noted in Table 2 would appear to be an enormous undertaking. On the other hand, osteopathic graduates markedly increased their portion of FM positions from $11.3 \%$ in 2010 to $32.3 \%$ in 2020 , a $415 \%$ increase in 10 years, or 112 per year. The percentage of DO FMfilled positions versus all DO-filled positions increased from $18.7 \%$ in 2010 to $23.3 \%$ in 2020 . With the DO match filling $32.3 \%$ of FM positions while $23.3 \%$ of all DOs who matched in any specialty were in FM, this latter figure comes very close to the goal of $25 \times 30$.

The goal of $25 \times 30$ set by the FMAH initiative did not include international medical graduates (IMGs), US or non-US, perhaps because it would be difficult to influence specialty choice when people train in a different country and different curriculum. However, US IMGs (US residents who train outside the United States, predominantly in Caribbean-based schools) filled a little over $18 \%$ of all filled FM PGY-1 positions in both 2010 and 2020 , while non-US IMGs filled $16.8 \%$ and $9.4 \%$ in the same years, respectively. Together they filled $27.6 \%$ of all filled PGY-1 FM positions in the 2020 match. Since these applicants successfully competed for over $25 \%$ of available FM PGY-1 filled positions and eventually will contribute to a more robust US primary care workforce, they should not be ignored. Also, if IMGs are not to be considered in the $25 \times 30$ goal, then the numbers needed to achieve the $25 \%$ goal places an even greater burden on the MD and DO applicant categories. The US MD FM fill rate increased from $7.8 \%$ to $8.5 \%$ from 2010 to 2020 . In the same time period the percentage of all PGY-1 positions that were

Table 1: Comparison of Family Medicine Match Results 2010 to 2020

\begin{tabular}{|l|c|c|c|}
\hline & $\mathbf{2 0 1 0}$ & $\mathbf{2 0 2 0}$ & Change \\
\hline Number of programs & 454 & 706 & $55.6 \%$ \\
\hline Number of positions offered & 2,608 & 4,662 & $78.7 \%$ \\
\hline Number of positions filled & $2,384(91.4 \%)$ & 4,313 & $80.9 \%$ \\
\hline Fill rates & & & \\
\hline US MD FM/all FM & $1,169 / 2,384(49 \%)$ & $1,543 / 4,313(35.5 \%)$ & $-13.5 \%$ \\
\hline US MD FM/all US MD & $1,169 / 14,992(7.8 \%)$ & $1,543 / 18,108(8.5 \%)$ & $0.7 \%$ \\
\hline DO FM/all FM & $270 / 2,384(11.3 \%)$ & $1,392 / 4,313(32.3 \%)$ & $21 \%$ \\
\hline DO FM/all DO & $270 / 1,444(18.7 \%)$ & $1,392 / 5,968(23.3 \%)$ & $4.6 \%$ \\
\hline US IMG FM/all FM & $439 / 2,384(18.4 \%)$ & $787 / 4,313(18.2 \%)$ & $-0.2 \%$ \\
\hline US IMG FM/all US IMG & $439 / 1,749(25.1 \%)$ & $787 / 3,154(24.9 \%)$ & $-0.2 \%$ \\
\hline Non-US IMG FM/all FM & $400 / 2,384(16.8 \%)$ & $405 / 4,313(9.4 \%)$ & $-7.4 \%$ \\
\hline Non-US IMG FM/all non-US IMG & $400 / 2,881(13.9 \%$ & $405 / 4,222(9.5 \%)$ & $-4.4 \%$ \\
\hline FM fill/all NRMP fill & $2,384 / 24,378(9.7 \%)$ & $4,313 / 32,415(13.3 \%)$ & $3.6 \%$ \\
\hline
\end{tabular}

Abbreviations: FM, family medicine; IMG, international medical graduate; NRMP, National Resident Matching Program. 
filled by FM individuals from all four applicant categories increased from $9.7 \%$ to $13.5 \%$. This appears to be due primarily to the increase in the DO pool. While this is a laudable increase, it is far from the goal of $25 \%$.

Table 2 examines a 2030 match extrapolating what it would take to go from 2020 to 2030 using a baseline of 2020 in order to get to the goal of $25 \times 30$. The total applicant pool in each category and the total number of filed PGY-1 positions are kept the same for 2030 as they were 2020 , based upon the assumption that a major increment in overall GME funding/positions/programs is unlikely to occur due to the pandemic-related economic recession, caps on existing programs, and questionable expansion of more medical schools. Expansion of the 2020 numbers would also make attainment of the $25 \times 30$ goal even more difficult. If there were $25 \%$ more total GME programs available in $2030(40,000$ vs 32,000 ), then the $25 \%$ goal would become 10,000 individuals needed to choose FM vs the 8,000 needed if there is no expansion of positions.

If all four applicant categories are included, FM would need to fill 3,970 (88\%) more positions in 2030 compared to 2020 to achieve the $25 \%$ goal, with the greatest challenge in the MD category. Here 3,024 (196\%) more positions would need to be filled to get to $25 \%$ of the total MD applicant pool. The DO category would only need to add $100(7.2 \%)$ more filled positions to get to $25 \%$ of their total DO applicant pool. If only the MD and DO categories are considered, then the overall number needed in 2030 to reach $25 \%(8,103)$ is subtracted from the actual MD and DO combined 2020 fill number $(8,103-2,935)$, giving a result of 5,168 more FM positions that would need to be filled in 2030 by only US MDs and DOs. This would be reduced by 1,378 if the IMG categories are added $(5,168-3,790=1,378)$.

While the assumptions made here may not be exact, the relative degree of needed change to get to $25 \%$ is obviously large. One mechanism to achieve a shift of this magnitude would be movement of existing GME funding away from other specialties to FM since the overall number of GME positions is likely to remain static. Another possible mechanism is to increase the number of PGY1 positions in existing programs by two positions per year, leading to 1,412 new positions $(706 \times 2=1,412)$. Problems with this approach might include hospital-sponsored programs that are at their cap in GME CMSbased funding, program accreditation status, the ability to provide enough patient numbers for more residents, and faculty numbers. All of this makes significant GME or FM GME expansion less likely in the future.

\section{Discussion}

The data from Tables 1 and 2 raise numerous practical questions. The goal that $25 \%$ of US MD and DO choose FM residency programs is probably unrealistic (barring major changes in US health policy and funding) and too limiting in terms of getting to a robust primary care workforce in this country. IMGs should be included since they filled $27 \%$ of all FM filled PGY-1 positions in the 2020 match. Failure to include them in the $25 \times 30$ calculations increases the burden on the $\mathrm{MD}$ and DO pools and ignores the contribution that IMGs will make to the FM/primary care workforce and the health care of Americans in the future.

Since FM departments and residency programs do not control the majority of GME funding sources (hospitals/health systems, state governments and community health centers control most and allocate them to meet their priorities), then how can family medicine persuade these entities to change priorities and move more resources to increase FM programs and positions? Departments of family medicine have made substantial commitments of resources, time, and effort to teach and role model family medicine principles and attitudes to students, but the results over the last 10 years have been disappointing. The US MD fill rate of FM positions declined from $49 \%$ to

Table 2: Changes Needed to Achieve 25x30

\begin{tabular}{|l|c|c|c|c|}
\hline \multicolumn{1}{|c|}{ Category } & Calculation & 2030 Goal & 2020 FM Actual & Needed Increase \\
\hline & \multicolumn{2}{|c|}{$\begin{array}{l}\text { Formula: } 0.25 \times \text { total \# filled positions in each category=2030 goal-2020 } \\
\text { actual=needed increase }(\%)\end{array}$} \\
\hline All NRMP positions & $.25 \times 32,414=$ & 8,103 minus & $4,313=$ & $3,790(88 \%)$ \\
\hline US MD & $.25 \times 18,106=$ & 4,567 minus & $1,543=$ & $3,024(196 \%)$ \\
\hline DO & $.25 \times 5,968=$ & 1,492 minus & $1,392=$ & $100(7.2 \%)$ \\
\hline Combined MD/DO & $.25 \times 32,414=$ & 8,103 minus & $2,935=$ & $5,168(120 \%)$ \\
\hline US IMG & $.25 \times 3,154=$ & 788 minus & $787=$ & $1(0.1 \%)$ \\
\hline Non-US IMG & $.25 \times 4,222=$ & 1,056 minus & $405=$ & $651(161 \%)$ \\
\hline All four categories together & $.25 \times 32,414=$ & 8,103 minus & $4,313=$ & $3,790(88 \%)$ \\
\hline
\end{tabular}

Abbreviations: NRMP, National Residency Match Program; IMG, international medical graduate.

Note: MD/DO increase is 5,168 - all four categories of applicant together needed increase - 3,790=1,378 reduction in number needed on MD/DO side alone to achieve $25 \%$ in 2030 . 
$35 \%$ over the $2010-2020$ time span and the percentage of US MDs filling FM positions as a proportion of all US MD graduates filling positions increased from $7.5 \%$ to only $8.5 \%$. This clearly suggests that departments of FM do not have the needed power and influence to achieve $25 \times 30$ goal. It speaks volumes about the admissions, culture, and hidden curriculum, particularly of allopathic medical schools.

One strategy is to continue to gather and more publicly present data on issues that can be addressed by a much more predominantly primary care workforce (eg, health care costs, health outcomes, and health disparities data). Data from Baicker and Chandra at Dartmouth using Medicare data discovered that those states with more general practitioners used more effective care, had lower spending and higher quality care. $^{7}$

Barbara Starfield studied the health systems of different countries, finding that those with a strong primary care workforce had lower average costs and generally healthier populations. ${ }^{8}$ A strong primary care workforce was generally considered to be comprised of nearly $50 \%$ primary care physicians. FMAH used $40 \%$ as an appropriate goal for the primary care workforce.

In an Association of Departments of Family Medicine listserv discussion regarding NRMP outcomes, many people felt that FM salaries have not kept up in the marketplace, thus disincentivizing students from choosing family medicine. Lee Green, MD, Chair of University of Alberta Department of Family Medicine offered some observations: "Increasing pay for family medicine can make a difference but it won't happen or be sustained until the (social) norm is changed.... In all advanced nations there is a broad social consensus that health care should be equally available to all...that society quickly realizes that the most effective and efficient way to do it is a primary care system." Jerry Kruse, MD, MSPH, notes that FM interest thrives when the ratio of FM income to specialty income is $80 \%$ or higher. ${ }^{10}$ Given the market-driven nature of the American health care system, this ratio is unlikely to be achieved and sustained.

Limitations of this article consists of using only 2 years of NRMP data 10 years apart to imply cause and effect, and that this is an ongoing trend. Assuming that GME funding and the number of physicians available will remain static over the next 10 years is problematic, but perhaps less risky than assuming there will be large increases in funding or decreases based on the unknown impact of the coronavirus pandemic on the health care system and on the economy as a whole. Medical student specialty selection is a complex subject that deserves a detailed discussion, but that is beyond the scope of this paper. However, ideas that deserve further exploration include what factors in osteopathic schools are associated with high selection of FM among their graduates, practicebased work in a relative value-dominant system, employment models, and scope of practice.

Lastly, conversations about the development of a plan for universal health care are increasing in volume and substance. Family medicine needs to be involved in every aspect in order to be at the table when national goals are established, workforce planning with resource allocation is debated, and equitable access for all is defined. Until such a plan is firmly in place, the goal that $25 \%$ of all medical students will find a position as an FM PGY-1 resident is unlikely to be realized. However, working toward that goal and embracing some of the steps noted above might move the needle in that direction. Considering the forces that brought FM into existence, the words of Gayle Stephens in 1982 come to mind: "the family practice movement has succeeded in the decade just past because we were identified with reforms that were more pervasive and powerful than ourselves."11 FM does not have the power and influence today to make $25 \times 30$ happen. Continuing to document the impact of FM on health, access, equity, and cost over and over again is absolutely necessary so that FM will be optimally positioned to fully participate in the "pervasive and powerful" reforms of the future.

ACKNOWLEDGMENTS: The author thanks Brenda David, Chris Antczak, Dr Lee Green, and Dr Jerry Kruse for their support of this project.

CORRESPONDENCE: Address correspondence to Dr Alan K. David, 8701 Watertown Plank Rd, Milwaukee, WI 53226. 262-391-4406. akdavid@mcw.edu

\section{References}

1. Kelly C, Coutinho AJ, Goldgar C, et al. Collaborating to Achieve the Optimal Family Medicine Workforce. Fam Med. 2019;51(2):149158. doi:10.22454/FamMed.2019.926312

2. Ofri D. Why Are Nonprofit Hospitals So Highly Profitable? New York Times. February 20, 2020. Accessed February 20, 2020. https:// www.nytimes.com./2020/02/20/opinion/nonprofit-hospitals.html

3. Interlandi J. Employer-Based Health Care, Meet Massive Unemployment. New York Times. June 29, 2020. Accessed August 27, 2020. https://www.nytimes.com/2020/06/29/ opinion/sunday/coronavirus-medicare-for-all. html.

4. Power (social sciences and politics). Wikipedia. https://en.wikipedia.org/wiki/Power. Accessed November 6, 2019

5. National Resident Matching Program. www. nrmp.org. Accessed January 15, 2020.

6. National Resident Matching Program. www. nrmp.org. Accessed January 15, 2020.

7. Baicker K, Chandra A. Medicare spending, the physician workforce, and beneficiaries' quality of care. Health Aff (Millwood). 2004;23(Suppl Web Exclusives):W4-184-97. doi:10.1377/ hlthaff.W4.184

8. Starfield B. New paradigms for quality in primary care. Br J Gen Pract. 2001;51(465):303309.

9. Association of Departments of Family Medicine. www.adfm.org. Accessed September 10, 2020

10. Kruse J. Income ratio and medical student specialty choice: the primary importance of the ratio of mean primary care physician income to mean consulting specialist income. Fam Med. 2013;45(4):281-283.

11. Stephens GG. The Intellectual Basis of Family Practice. Tucson, AZ: Winter, 1982. 